\title{
Yearning for Care? Rethinking Paternalism in Contemporary China from Migrant Worker's Perspective
}

\author{
I-Chieh Fang \\ National Tsing Hua University
}

A great deal of research work available on the situation of migrant workers in post-Mao China focuses on how the working conditions generate anger among the migrant workers, which causes strengthening of their 'horizontal' networks and their informal protection organizations. This paper shifts the attention from 'horizontal' to 'vertical' networks in factory and attempts to figure out what are the mostly likely ways to change China's state-society relationship. I argue that the factory context has strongly been shaped by parental absence and dysfunctional families following mass migration. When migrant workers' family experiences are about unrequited yearning for care and intimacy, it appears that 'fatherizing' of authorities of various kinds which are seen as (being able to be) caregivers and effective allocators of resources may be the proper response to the near constant absence of close family. Under such circumstance, the rise of individualism could paradoxically fuel paternalism.

Keywords: migrants, caring, family, networking, life strategies

\section{INTRODUCTION}

Rich literature is available regarding situation of migrant workers in post-Mao China. Much of the research work on Chinese migrant workers focuses on their status as victims of the system: low wages, poor working conditions, temporary contracts, little bargaining power, no welfare entitlements, no basic protections under the household registration (hukou) system and forced circulatory movement between city and village. In short, they are victims of exploitative enterprises and their close ally, the Party-state (Chan 2001; Chan and Wang 2004-5; Pun 2005; Solinger 1999).

Such working conditions generate migrant workers' 'deeper sense of anger and dissatisfaction' (Pun and $\mathrm{Lu}$ 2010: 512-3) and 'has spontaneously nurtured strikes' by the second generation of migrant workers in south China (ibid 2010: 56) Pun and Lu claim, supported by a number of other scholars, that 'taking a specific path of proletarianization, the second generation of peasant-workers have gradually become aware of their class position and have participated in a series of collective actions (Pun and Lu 2010: 512). The intrinsic tension and potential conflict between developmental state of China and social groups of migrant workers has thus been crystallized around the striker's perspective:

The agents of migrant workers need to develop a strong common identity and pursue their interests collectively and consciously - but, at the same time, China's developmental state continues to restrict the opportunities of such groups to organize 
themselves. Labour relations and state-society relationships are dynamic and constantly changing. (Zhu 2004:1033)

According to Zhu, the way moving forward is the extension and strengthening of 'horizontal' networks among migrant workers and their informal protection organizations, which are believed to be the mostly likely way to change China's state-society relationship. Hence, China's future seems to depend on how state, unions and migrant workers find a compromise (Zhu 2004).

Nonetheless, there is another prevalent perspective of state-market relationships of migrant workers that is seldom discussed. According to the fieldwork I conducted in Shenzhen, the exploitative alliance of state and market is not that clear for most of migrant workers. What many of them strongly believe is that the need of an authority to protect workers from the evil market (a western invasion) like a strong, firm and powerful father. This also shapes intra-factory relationships with authority figures and fellow workers. In this model, migrant workers attribute their inferior situation to competing peers rather than authorities. Their chosen forms of resistance and their life strategies to escape their unpleasant working conditions are guided by a reasoning which is very different from that of the strikers'.

In this paper, I argue that the factory context has been strongly shaped by parental absence and dysfunctional families in the wake of mass migration. ${ }^{1}$ Young migrant workers who grew up as liushou ertong (children 'left behind') are at the same time surrounded by mass media and mainstream propaganda dominated by the neo-liberal desires for intimacy and care (Rofel 2007) and the privacy-oriented family model (Yan 2003). When migrant workers' family experiences are all about unrequited yearning for intimacy, it appears that 'fatherizing' of state or authorities of various kinds, seen as (being able to be) caregivers (to young migrant workers) and effective allocators of resources, is the proper response to the near constant absence of close family members in an era where 'desiring China' (Rofel 2007) is still fighting with the 'evil market'.

Anthropological study shows that even in the most developed countries, kinship systems still serve as obvious metaphors of power, inequality, and belonging (Carsten 2004; Foucault 1991). Nationalism in particular often goes hand in hand with kinship metaphors. Nationalist discourses frequently employ the language of kinship to make differences appear natural, and the nation-state also extends kinship morality to non-kin when claiming its sovereignty. By employing family as a model for power relations, the nation-state can both naturalize hierarchy and yield a sense of belonging.

In this image, the state, like parents, nurtures their children. State (in the shape of parents) is more responsible, stronger, wiser and more experienced than their citizens (children). Therefore, the decisions should be made by the state and the citizens should simply follow them. In addition, it implies the relation between state and its citizens is not only bound by mutual obligations but it is also characterised by affection and love (Anderson 1983; Carsten 2004). It evokes feeling and passions that people could die for (Anderson 1983). To view state-society relationship from this angle might help to explain some migrant workers' perception of Chinese Party-state.

Similarly, even though capitalism has reached a late stage, paternalism is still prevalent. Neoliberalism requires new form of labor arrangements whose implementation needs to rely on the discourse of traditional paternalism (Sanchez 2012). In China, paternalism is always haunting as a socialist legacy (Rojas 2016). After the reform and opening up in 1978, the party state still adopted the development strategy of the paternalistic system (Liew 2005: 335), which made the Chinese system always mixed with different systems, practices and disciplines. The elements of Mao's governance such as the central economic plans and the ideology of the socialist paternalism are intertwined with the liberalization of the market economy (Nonini 2008). Paternalism is not just for governance, but also an expectation of common people. The consumer idealizes the paternalistic management model, which regards the well-being of citizens as the responsibility of the leaders. When the problem occurs, instead of appealing to the law, people look towards the state to intervene and cater for any misconduct. It shows that paternalism, as a moral claim that emerged from social and historical contexts, has not disappeared under the new economic model (Kuever 2019). 
On the other hand, Chinese research scholars have observed in recent years that with the rise of individualism, patriarchy is getting wane (Yan 2003). It has become an important question: Will paternalism disappear with a new generation of migrant workers? This paper analyses the situation of migrant workers through ethnographic data, and argues the broken family and 'evil market', which are experienced by most migrant workers, will make the rise of individualism fuelling paternalism in the factory. This article attempts to illustrate the reasons behind this phenomenon.

\section{MIGRANT WORKERS, FACTORIES AND METHODOLOGY}

The main methodology I adopted to collect the data is participant observation. I spent twelve months conducting fieldwork in China (First time October 2007-October 2008 and following up fieldwork from 2012-2018), primarily in an electronics factory in Shenzhen's Special Economic Zone. I refer to this factory as THS. My most important informants were the young migrant workers of THS. My roommate in the factory dormitory, Xioahua, was particularly important as she was especially willing to tell me her story and bring me into her social circle. She also took me to her home town in Hubei province during the Chinese New Year for three weeks. I therefore met her family, some of her relatives, and some of her classmates. I met her uncles, aunts and grandparents at their homes during my stay. I also visited the nearby town several times with Xioahua and her laoxiang (friends from the same native place). These opportunities to understand her story and her situation in detail gave me insights into the position of migrant workers (especially female) which were further confirmed by my interactions, formal and informal, with other factory workers.

While staying at THS, I was allowed to walk around the factory freely and talk to workers spontaneously. I attended training courses with workers and sat with them during the recruitment fair. I had my own desk, first in their administrative section and later in the Quality Control office. I normally sat beside the assembly line to observe the workers working there. I shared a room in the female dormitory with three other workers. I ate in the canteen with the workers, three meals a day and seven days a week. They invited me to shop with them in the nearby supermarkets after work and to go out for activities at the weekend, such as climbing hills and visiting scenic locations.

I formally interviewed 41 workers at the THS factory. My policy was to ask the group leaders in advance to make sure my interview would not cause any disruption to the factory's work. The workers I interviewed in THS came from nine different provinces, and ranged in age from 16 to 42; 17 of them were male and 24 females. Nine of them were married. 38 of them had siblings - an important point while only one was a single child. ${ }^{2}$

The data I collected during the course of fieldwork focused on a number of very different themes. First, I collected data about the 'reality' these workers faced: what was happening in the society around them (e.g. the financial crisis, new labour laws etc.), the immediate environment of migrant workers, their background, the experiences they have gone through and the social roles they fulfilled. Second, I collected data about the desires, dreams, and hopes of young migrant workers which they wanted to realize being migrants. Third, I collected data about the decisions they made in making their choices in life and the motives behind them, in their own interpretation. In this way, I was able to collect data about how migrant young workers perceived the 'realities' they face, how it influenced their decision making, and how they responded in practice.

Before explaining my data and analysis, first I want to give a brief introduction to the factories I attended. The SEZs of Shenzhen is actually adjacent to the city of Shenzhen, not within the city properly. If workers wanted to go to the city, it took around one hour by car to get there.

The THS factory in Shenzhen was an electronics factory owned by a Taiwanese businessman. There were around 122 workers in total, 52 male and 70 female. The largest number of workers came from Henan (25 people, male 13, female 12). The second largest group was of the workers from Hubei (19, male 6, female 13). Altogether, there were workers from 17 different provinces.

The owner was around 40 years old. He grew up in Taiwan and got his Masters degree in engineering from Japan. He still maintained close connections with Japanese technicians who were 
invited to THS to conduct training from time to time. The owner's family was in Taipei. His business partners were in Taiwan too. Therefore, he did not always stay in China, and had to go back and forth between China and Taiwan several times a year. To achieve efficient management, he asked all clerical workers and managers to install Skype on their computers and stay online during working hours. In that way, he could give orders by Skype if necessary.

THS was not dominated by 'local' workers with permanent contracts and speaking an exclusive dialect. In this factory, the power relations among migrant groups from different provinces were more dynamic. Although the factory was located in Shenzhen, Guangdong, the workers from Guangdong did not form a special level of internal stratification. On the contrary, the strongly accented Mandarin of Guangdong workers made it sometimes hard for them to communicate with the owner of factory, who could not speak Cantonese. For the owner, the workers from all the provinces were all more 'local' than him. Therefore, workers from every province seemed to have the chance to be chosen to be a high flyer. The dominant imaginative division among workers was probably 'mainlanders' versus 'Taiwanese'. Taiwanese were seen to be the special group because they had the relevant 'localistic relatedness' (in contrast to localistic 'otherness') to the owner, and in fact, they did get special treatment in Taiwanese-run factories generally.

The workers here were generally younger, the average age being 20 years only. $78.04 \%$ of them were unmarried. Their average educational background was junior high school certificate. Some of them with university degrees were in high-rank managerial positions. When they calculated the costs and benefits of their migrant journey, income and expenses were seldom the priority. They imagined a good future at the end of their journey and seemed to truly believe it would come one day. But, at the same time, they changed jobs quickly. Once they felt they had been treated unfairly or wrongly, they just quit the job and returned home, hoping their next job would be better. The hope of the future, the short cycle of work and the continuous 'job hope', meant that being a worker did not seem to be their main identification; it seemed to be more the practical ladder they must climb in order to achieve their dreams (normally, to danglaoban [literally, be a boss, be a business owner]).

\section{THE 'EVIL MARKET’ AND THE (NECESSITY OF) STATE-LED MARKETS}

Let me begin with the dormitory life of factory workers - I myself shared these dormitory conditions in the spirit of experiencing as far as possible the life of the young migrant workers. I gradually learnt that migrant workers typically maintained a fine, but, firm boundary between themselves and others in both their public and private lives. If neither of two people intended to build up a friendship between them beyond a kind of 'managed relationship', they might treat each other with incredible indifference, as though the other one did not exist. In effect, they deny any right to interfere in another person's behaviour, but, equally (or by the same token) having no responsibility for them either. It will explore here further with reference to the question of workers' feelings of mistrust towards their new environment, both inside and outside of the factory.

Within the factory, there are various reasons why workers might feel mistrustful of their new surroundings and their fellow workers, such as the relative impersonality of factory life compared with the social life outside (Carrier 1992). One more specific reason workers were mistrustful of each other was that many, if not most, of them had themselves at some point used fake CVs and documents to apply for jobs. Clerical workers and managers also routinely used false information in their CVs.

Working (and living) in an environment surrounded by people with vague and hard-to-trace pasts, it is easy for migrant workers to conclude that others are not trustworthy. At the same time, 'scams' seemed to be constantly happening around them. Migrant workers were vulnerable to deception in other ways outside the factory. They might be tricked into buying fake goods and fake foods. They might get robbed on their way home. Young men (who, in fact, looked similar to the young men in the factories) sometimes waited in the street to steal their wallets and mobile phones. Even those who did not experience serious problems themselves had heard stories about people who had been murdered or raped in nearby streets and workplaces. Migrant workers described the untrustworthy, potentially dangerous, social environment 
around them as the luan (chaos, disorder) that resulted from the implementation of market and economic opening up. Although luan in the wake of marketization erodes rigid social stratifications on rural-urban dichotomy and offers them the chance of upward mobility which brings them from rural village to Special Economic Zone, it also puts them into the vulnerable, untrustworthy, and uncertain situation.

Judging by Chinese history, Chinese people constantly harboured contradictory feeling toward disorder and the market: it brings feelings of freedom but also the guilt of immorality, like the devil seducing people to sink into their own weakness. The greatest social evil in the Confucian dogma was disorder and chaos (luan). Markets - and here very much concretised as actual physical markets - were a possible source of disorder. Therefore, they are suspected (Stockman 1992: 269). In addition, if merchants are able to make big money in the markets, they could possibly become significantly wealthier than their social superiors. It introduces 'a disturbing element of status inconsistency into the social hierarchy' (Stockman 1992: 269). Thus, for the authorities, it is undoubtedly necessary to control the market and 'to ensure the orderly conduct of their proceedings' (MacCormack 1990). Intriguingly, from the viewpoint of farmers and villagers, the most attractive part of the market was not in pursuing self interest and behaving as a 'rational economic man'. They actually enjoyed the atmosphere of disorder and chaos (Crissman 1972: 243). Crissman makes a further statement that the market is a kind of 'deviation' which can be expressed in the Chinese term renao (hustle and bustle). Going to market is for noise, bustle, sociability and fun (Stockman 1992: 269-70). This also explains why an apparently ideal site for a standard marketing town might not actually be very popular (Crissman 1972). 'The market' for Chinese people means not only the place for exchange but also the place for freeing themselves from social hierarchy, order and morality. They enjoy the atmosphere of renao, in which a person is not expected to bind with the cultural norm as usual. They are temporarily allowed not to be a proper social person and to show their own emotions, and express selfishness naturally and freely. For the authorities, this type of 'person' is dangerous. If all the people they ruled acted in this way, it would undermine the social stability. Confucianism, which preached a specific type of 'concept of self', could be seen as an ideology for preserving authority by suppressing the ruled people acting as 'free' agents. 'Self' surrenders to 'social role'. It makes emotions and affection to be placed in rather interesting positions in the social life (Kipnis 1997; Potter and Potter 1990). Regardless human nature or not or to what extent it represents the true self, personal emotions should be expressed according to 'li' (book of rites) to fit properly into the social context. For example, a son should be submissive to the anger of his father. But, if the father shows too much anger and intends to hit or hurt his son, it could compromise his proper fatherhood. Therefore, the son should run. To behave like this, the son won't compromise his father's fatherhood. That's the true filial piety. Besides, parents should not be too close to their son, because intimacy will result in uncontrollable emotions which risks violating the proper behavior father and son should behave (Kipnis 1997). Self here is danger and should be monitored all the time in order to behave 'properly' in one's social 'role'.

The description above is probably still valid for migrant workers' experience today. They come for the freedom, autonomy and opportunities which are believed to be unavailable in the rural home town. But, living in a relatively compact space with limited personal privacy, migrant workers must learn to deal with the untrustworthy, potentially dangerous, social environment around them. Later, I will explain the strategies they generally use. But, before that, I try to show that in Chinese history (both before and after 1949) there is nothing new in the state/empire to take the stance of taming the 'evil' market, a symbol of disorder and immorality, to put everything back into order and to maintain social stability.

In the Mao era, Mao also stressed on moral motivation, instead of material, in economic transactions (Stockman 1992, 268). He 'place[d] a high premium on politico-moral judgments of personal worth' (ibid: 268). For example, personal development and the future are not dependent on technical skills or intellectual abilities, but are based on the political and moral 'virtue'. Shirk (2010; 1982), who analysed the dynamics of contests for virtue during the Culture Revolution, used the term 'virtuocracy' to denote the idea that personal life chances are determined according to 'judgments of virtue'. Thus, Stockman argued that this mechanism by which moral force suppresses economic transactions is the main factor which explains why the Chinese economic system cannot "totally be uncoupled from the "lifeworld" 
(Stockman 1992: 272). Since the Song dynasty, the 'Chinese economy had become increasingly commodified' accompanied by the development of complex bureaucratic state institutions. In addition, "money [would] also be used for a wide range of transactions and there is a complicated network of local markets, periodic markets and temple fairs (Skinner 1964-65). Thus, if China met all the criteria required for the development of capitalism, why did it not happen? The Chinese authorities' use of ideology to stigmatise commerce is one of the reasons for this (Stockman 1992). Similarly, Gates (1996) proposes a mechanism which also emphasizes the state's intrusion. Drawing on semi-Marxist categories, she argues that there were two modes of production, Petty-Capital Mode of Production (PCMP) and the tributary mode of production (TMP), which created a special form of commodity production that did not lead to capitalism. That PCMP could not become authentic capitalism partly because it relied on mechanisms 'organized in the idiom of kinship'. More important, however:

The petty-capitalist mode remains subordinated, subsumed within the tributary mode, because the kinship/gender system crucial to petty capitalism is defined and maintained principally by the ruling class as an aspect of its hierarchical control of the entire social formation. (Gates 1996: 8)

Maintaining 'its hierarchical control of the entire social formation' (Gates 1996: 7) was thus privileged above economic expansion, with Confucian ideology playing an important role also tarnished commerce and market transactions.

In the next section, I will look through the lens of the family background of migrant workers and from this angle argue why a caring fatherly state/authorities features are there in their desires.

\section{CHILDREN LEFT-BEHIND: A GENERATION YEARNING FOR RESPECTABLE, CARING PARENTS}

Starting with, or before, their parents' generation, rural people began to crowd into nearby towns or cities farther away on a large scale to dagong (work for a salary). ${ }^{3}$ Consequently, under the current hukou system[household registration system], about half of the migrants I met grew up as liushou ertong ('children left behind') (Ye and Pan 2011) and were taken care of by their grandparents or uncles/aunts, seeing their parents only during the Chinese New Year period, with the result that they did not receive much care and attention during childhood (at least this is what they say).

Xioahua's parents were 'second-generation' migrants ${ }^{4}$ and, Xioahua, the eldest child, was one of the liushou ertong, brought up by her grandmother while both her parents left home in order to earn money. She had been especially shy and intimidated at school because there were no adults in the village able to protect her if she was bullied. Xioahua herself left home when she was 14 years old, not too long after she dropped out of junior high school. She first went to Shanghai and then Shenzhen, following her cousin, Ling. ${ }^{5}$

My experience is that young migrant workers generally do not pay much heed to their parents' suggestions because they feel that the experiences their parents went through when growing up are not applicable or relevant to their own lives. As first- or second-generation migrant workers, parents were generally married before migrating out. They left mainly in order to earn money to support their families, who still lived in rural areas. But, for new generation migrant workers, the problems they need to deal with during their migrant journey are mainly about sorting out their future, a situation their parents have never encountered and thus have no experience to share with them. In addition, given that the world is changing so quickly, most parents of new generation of migrant workers, even though they are migrant workers too, know almost nothing about their situation in places like Kunshan or Shenzhen. This means that the new generation workers have to 'figure out the future' for themselves from the vantage point of places like Shenzhen or Kunshan.

Indeed, parents frequently have to learn things from their children, a phenomenon known as 'cultural feedback' (Zhou 1999). The parents of young migrants, typically rural peasants, lack the confidence to 
insist that their children obey their instructions, because they rely to a great extent on their children's knowledge of the modern world. Although parents still shoulder the responsibility of guiding their children as they grow up and become independent, and the children are still supposed to show respect and filial piety to their parents, the situation of these parents implicitly pushes the young peasants to seek other role models to follow for a better life. Considering their parents' experiences to be mostly irrelevant to their lives, young migrant workers have to grow up, to some extent, without effective guidance from their parents. Young migrants sometimes quote their cousins or colleagues in response to lectures from their parents.

Obviously, actual kinship ties do not, in fact, disappear in the factory. Even though they are far away from their home town, they do not usually reject the support they gain from family ties. Actually, they cannot help doing this. Even in the factory, where kin are sometimes working together, hierarchical differences of age still count: the elder relative can lecture the younger or ask them to wash their clothes or sweep the room for them. The younger one can tell the elder their needs and problems and the elder should resolve them. In some cases, the younger relatives hand over their salary to the older relative to save the money safe for them and decide how much they can 'withdraw'.

However, kinship support, it seems, function in a low-profile way compared to networking, guanxi (relationship), or 'fictive kinship', which are valued more highly by the workers I met. Although cousins were important to them, young migrant workers hope that their social relationships can go beyond the given world of kin and seek to extend their social networks by building up friendships with strangers. Hence, my argument is that the networking, guanxi (relationship) or fictive kinship they strive to establish is mainly to make up for absence of their parents. In short, they are seeking a caregiver.

Researchers argue that in post-Mao China the mass media and mainstream propaganda are dominated by the neo-liberal desires for intimacy (Rofel 2007) and privacy-oriented family model (Yan 2003). But, when migrant workers' family experiences are all about unrequited wishes for intimacy, how do they reconcile the contradiction between their private reality and the (new) social ideal? In the factory context, the absent parents and dysfunctional family, it seems to me, had changed the social relationships within the factory. Workers' 'consent' is not manufactured by the labour process as Burawoy (1979) argues. Rather, it links to the 'liminality', uncertainty and untrustworthiness that workers confront during economic transition, which fosters not only worker's consent but also their 'filial piety' by projecting parent-child relationships onto their relationship with their supervisors.

Coping with uncertainty and untrustworthiness is a phenomenon commonly prevalent in many societies in transition. Religion and magic often step into the vacuum to provide the lost measures of morality and meaning (Humphrey 2002). Otherwise, obsession with consumerism is another way to get comfort (Shevchenko 2009). However, in the Chinese factory, I see an alternative picture. Compared to searching for a fatherly figure, religion and consumption play less prominent roles as strategies in coping with uncertainty and untrustworthiness.

\section{'TIBA' (SPECIAL PROMOTION), PARENTAL CARING AND 'FATHERIZING' AUTHORITY}

Under China's emerging market economy, young people are sometimes said to be developing 'neoliberal subjectivities' (Rofel 2007: 2). They talk openly about their 'hearts' (xinli, xintai) and their 'feelings' (ganjue) (Rofel 2007: 4). Individuals are not only presumed to possess emotions and desires but it is considered legitimate for them to express them and follow where they lead, in the pursuit of individual freedoms (Yan 2003: 239). Moreover, this is not just a phenomenon of the cities; rural people apparently believe they deserve such freedoms too (Yan 2003: 248). The family has become increasingly understood as a private conjugal unit relatively free from the judgments of the outside world (Yan 2003: 243). Young people now express their own opinions in public and do not need to feel afraid of being labelled as deviants when their opinions differ from those of others (Yan 2003: 244). They are prone to be anti-authority, in some respects (Yan 1999: 81).

However, when parental authority collapses in the rural household (as discussed above; see also Yan 2003), 'fictive kin' typically step into the vacuum. These young migrant workers absorb workplace 
ideology and propaganda with little hesitation or scepticism, yearning to be different adults than their parents. They are also prone to accept parent-like authorities rather than impersonal regulations and rules. They expected parental-like benefactors will assist them on their road of self-development and adulthood. They also call co-workers 'uncle', 'sister' or 'brother' and the working section 'our family', and expect that mutual reciprocity and caring will follow. Migrant workers seemingly 'privatize' and 'familiarize' the public sphere and 'colonise' the impersonal world of work.

The prevailing practice of tiba in the factory is the cultural means through which the workers cope with the potential dangers of market competition. Seeking/hoping for tiba is seeking to be cared for through cooperation as a risk aversion strategy. This is especially important under the neoliberal regime, in which individuals are regarded as autonomous and risks are shifted from governments and corporations onto individuals themselves (Ong 2007). When laws do not protect individuals' rights and the system does not treat social actors equally, the individuals from the bottom of society, such as the young migrant workers I met, confront bigger risks than people with advantages. They need caring/support from somewhere and they seek it by forming patron-client relationships with their superiors and developing a set of skills specifically geared to nurture these relationships. Based on their experience, they choose to adopt an 'obligation-reciprocity' mode as their economic strategy to overcome their disadvantaged starting position in the structure rather than demanding 'fair' - rule-governed and impersonal - treatment or more legal rights (for example via the ending of the hukou system). If this 'obligation-reciprocity' mode sounds reminiscent of practices more typically associated with traditional China, this is not due to nostalgia. It is because a fair and impersonal system for distributing resources in the factory is simply absent.

It is not only for protection but also the strategies for success adopted by migrant workers in the factory that may be said to be traditional, i.e. they are part of the traditional folk theory of success. In the family model, the emphasis is on cooperation, sharing, caring, and exclusion. Fairness and equal rights do not exist as such in this hierarchical society. The individual is never the unit making the decision or taking responsibility for the consequences of decisions. Family members are assigned different 'roles' and the 'self' must adjust to fit in with these roles. The family distributes the resources according to the role each person occupies and how much this role contributes to the collective goal and serves the household as a whole.

The crucial point here is that tiba - in effect, gaining access to opportunities through favours - is the thing that the migrant workers I met appear to seek the most. They do not, in my experience, focus on the injustices of the hukou system and demands that it should be abandoned or reformed, or more generally on the ways that inequality between urban and rural people might somehow be reduced. They focus instead on establishing themselves in a career through 'cooperation with authority'. Meanwhile, 'competition with fellows' as a way to establish their careers also does not appear to be how they are thinking. It is not that these young people have no experience of competition; on the contrary, the Chinese schooling system they have gone through is highly competitive, as is well known. But, in the factory, I will suggest, competitiveness is constrained by the dilemma surrounding 'sticking one's head out'. Tiba avoids this problem because it seems to involve the element of chance or being suddenly and unexpectedly granted favours.

However, in this sense, the competition promoted by the market paradoxically turns out to be comparable to siblings competing for their father's favours. ${ }^{6}$ It is the intention of authorities, rather than impersonal rules or regulations that decides the outcome of competition is not a new thing for Chinese people.

After the arrival of socialism, the foundation of familism in China was supposed to have largely been eroded (Yan 2010). It is said that, in the era of economic opening up, Chinese people no longer live under the ancestor's shadow (Yan 2003). Given the radical change that is happening in the Chinese family, with the power of youth rising while the authority of elders declining (ibid 2003), it may seem surprising to see the familism survived, in a sense, in the workplace. Yet, the competition among workers is surely 'under the ancestor's shadow', if ancestors are taken to mean all the figures of authority. The authorities are still able to "provide the ground work and the limitation for both the means and the objects 
of this competition' (Hsu 1971: 282) even under the marketised economics of modern China, where the Party-state is at the top of the hierarchy of authority of various kinds.

Transnational capitalism changes show that the 'ancestors' can now be chosen/changed through individuals' labour and effort. Like traditional ancestors, the enterprise ancestors do not necessarily care whether their offspring are capable, efficient or well-educated when they offer their blessing. To stick to the reciprocal obligations, to think for the betterment of the family/factory as a whole, to be flexible, loyal and submissive might, in the end, be more important. For some young migrant workers, to compete for the favouritism of 'enterprise ancestors' and to undermine the alliance of Party-state and private capital through personal networks, say through forming 'fictive kinship' or 'guanxi', rather than protestation and directly fighting against it, might be the more efficient way to demonstrate their resistance.

\section{DISCUSSION: MIGRANT WORKERS, BROKEN FAMILY, RESILIENT PATERNALISM AND STATE-SOCIETY RELATIONSHIP}

By thinking the authorities as a father and familizing the factory, migrant workers believe their situation is comparable to the unfavoured children in a big family, the losers in the competition for father's favour among siblings (which, in this context, generally refers to other social actors in the market conflict for the same resources, say urbanites, entrepreneurs, managers, sometimes even other migrant workers). In their interpretation, their current disadvantaged situation to large extent results from the bullying of those 'siblings' and so they put their hopes of change onto a more powerful authority, namely the fatherly state - a state imbued with love, care and compassion being able to sympathize with its people. The strategy they choose as rewarding in the mechanism of resource allocation is through pleasing father, through being filial children. This particular kind of reasoning to a large extent eases the intrinsic tension between migrant workers and the Party-state - and authorities of other kinds, notably within the factory. In addition, consequently, when migrant workers face their disadvantaged condition resulting from the alliance of private capital and the Party-state, horizontal collective actions are harder to establish (given the high turnover rate of workers and the uncertain, untrustworthy environment in the factory). They are susceptible to the (special) caring from authorities and more willing to cooperate with it.

If the state were a rational bureaucracy with laws and regulations applied to every citizens then this would go with tuantigeju (organizational mode of association; individualism) ${ }^{7}$ in Fei's definition (Fei 1992); but, this does not coincide with the image of state in migrant workers' minds. The state for them is more like a big family with siblings of various kinds. In China, the pattern of social relationship among siblings stresses 'differentiation', which is rooted in the fundamental Confucian principle, renlun (human ethics) (Fei 1992: 65) rather than 'equivalence'. The pattern of social relationships is seen as like the circles that appear on the surface of a lake when a rock is thrown into it. Everyone stands at the centre of the circles produced by his or her own social influence. Everyone's circles are interrelated. One touches different circles at different times and places (Fei 1992: 62-3). In such a picture, there is no room for fairness or equal rights since the line between public and private is relative and varies, depending on the social actor's position.

Migration reinforces the links between horizontal kin (like siblings, cousins) of migrant workers while largely breaking the vertical tie (like parent-child relationship). Young migrant workers thus yearn for unrequited parental caring generally. They seek for it in the factory in the urban setting. The ideal type of benefactors, who substitute for their rural parents as both their role model and caregiver, are supposed to offer them opportunities of upward mobility, material benefits, and also caring, intimacy and love. A perfect market, or a set of rules, might be able to provide the former; however, with reference to love, intimacy and caring it is impossible to offer.

'Familizing the factory', through which the implementation of impersonal laws and regulations is often displaced or weakened in favour of the personal networks based on loyalty, filial piety, love, caring and intimacy, could be put into the category of guanxi in the broadest terms yet these are also different in important ways. 
According to Yang, 'guanxixue involves the exchange of gifts, favors, and banquets; the cultivation of personal relationships and networks of mutual dependence; and the manufacturing of obligation and indebtedness (Yang 1994: 6)'. Guanxi networks demonstrate autonomy of society; through implementation of guanxi, the social actors can avoid the reach of the state. She claims:

At present the legal system is not enforced to protect society; there are virtually no legal, public, or institutionalized structures or associations that are not part of or subordinated to the state bureaucracy; public assembly and discussion, even in small groups, is difficult unless it is condoned by the state; and between social groups, there are very few public or formal horizontal linkage across geographic and institutional boundaries independent of the state. (Yang 1994: 288)

Since in China 'no institutionalized structures or associations ... are not part of or subordinated to the state bureaucracy', Yang argues that only if we use the concept 'minjian' to replace civil society (with emphasis on the formal and legal institutions of democracy), are we able to understand 'the basic social fabric from which social organizations are created'(Yang 1994: 289). What does 'minjian' mean and why does it matter? Yang explains:

Given a cultural point of departure quite different from that of the West, Chinese minjian will probably not find individual rights and citizenship the most fertile ground for its emergence of reemergence. Where the history of civil society in the West was propelled primarily by a discourse of rights, specifically, individual rights, the formation of a social realm outside the state in China, will most likely be fueled by a discourse of relatedness and obligations. In China, the cultural emphasis has not been on the abstract universal person, but on the person as defined in terms of relationships and roles. (Yang 1994: 288-89)

Therefore, in China, we should not expect an autonomous civil society emerging externally to the state. On the basis of guanxi network, which is 'a fabric based on a 'web of kinship' pattern', a form of agency/resistance which 'crisscross state-imposed institutions' (Yang 1994: 311) is present and a social order that can 'activate and organize itself' on 'a multiplicity of organizational principles' is about to emerge.

In this sense, we can argue that most migrant workers' subjects are still framed by guanxi subjectivity rather than individualistic subjectivity. Although migrant workers are not going onto the street to fight for their rights, they are resisting in the guise of a filiation relation toward the authorities. Young migrant worker yearns for tiba (special promotion) and cooperating with authority is fostering from such a mechanism. Such alternative could help them manoeuvre around the rigid exploitive structure and gain the care, love, and intimacy that they are longing for from parent-like figures.

However, - and this difference is very important - the phenomenon of mass migration, children left-behind and broken family seem to largely weaken the rhizomatic horizontal dimension of migrant workers' guanxi networks and reinforce the vertical dimension. The Chinese state here again has become both more elusive/spectral and more intimate to its subject (see Mueggler 1990). In such conditions, what forms of resistance are possible?

The Party-state/factory authorities seem to be making use of the kinship order and re-planting its organizational principles and administrative apparatus to legitimate a centripetal, hierarchical, filial and corporative mechanism of resources, to what extent will it be forwarded by migrant workers' 'familizing' friendship, i.e. forming fictive kinship, in the factory? 


\section{CONCLUSION}

It might be wondered, why, as compared to revitalizing religion or consumption activities, fatherly figures play such a dominant role? Apart from being left-behind in their childhood, I think we might also need to examine the role the state plays here. We cannot ignore that China has implemented economic reforms based on market principles but retains its 'socialist' political form. Unlike other post-socialist countries, the Chinese Party-state maintains strong influence and aims at providing the world with another set of values and ideologies (Leonard 2008: 117). It embraces neoliberal values selectively. When it encourages 'desires', 'feeling', and 'privacy', it also regulates them simultaneously in order to serve the state's agenda (see Anagnost 2004). When religion re-emerged in post-Mao China, it was 'nationalized' as the way Party assigned members to monitor all the legitimated churches.

The state's role in China is different from other capitalist societies. Resources in post-Mao China are still redistributed by authorities of various kinds rather than by the market. Meanwhile the Chinese Party-state stands at the apex of all forms of authority to 'lead' market. In this sense, it is not a surprise to see that 'neo-traditionalism' (Walder 1986) still exists and functions in Chinese factories. The 'father' is still protecting China from the harms of the evil market, culturally perceived as 'disorder and immorality' (luan) (Mann 1987).

The problem arising here will be: so long as supervisors/authorities of various kinds are treated like a father rather than an adversary, does this make the resistance offered by workers irrelevant to structural reform but, rather, individual? Fathers can be moody, treat their children in different ways regardless of fairness and justice. Father is allowed to be arbitrary, as long as he is capable of taking care of the family and children. When authorities are likened to fathers, consequently, no worker pays attention to regulations and rules and to check if they are being treated fairly. What kind of regulations can regulate supervisors' parental love, or how can you regulate how much love and care a father should give to his children?

We can easily argue the same point from the opposite direction: when laws do not protect individuals' rights and the system does not treat social actors equally, the individuals from the bottom of society, such as the young migrant workers I met, confront bigger risks than the people with advantages. They need care/support from somewhere and they seek it through forming cooperative relationships with their superiors and developing a set of skills specifically geared to nurture these relationships.

But, no matter which model is correct, the absence of social security and its implementation are crucial in shaping Chinese migrant workers' attitude toward the state, 'capitalist' enterprises and the form of resistance they would adopt.

\section{ACKNOWLEDGEMENT}

I-Chieh FANG is Assistant Professor at Institute of Anthropology in National Tsing Hua University, Taiwan. Her email address is icfang@mx.ntnu.edu.tw

\section{ENDNOTES}

1. Many rural families have lost its traditional function as a care and socialize unit for the children. According to my fieldwork, many migrant workers were grown up as so-called 'child-left-behind'.

2. Two of them didn't answer the question.

3. Background information about rural migrants going to the city for work can be found in John Knight's 'Labour policy and progress: overview' (Knight and Song 2005: 13-45).

4. In definition, first-generation migrants denote who for the most part had already married before migrating, had children in their home towns, and shifted back and forth between their urban and rural bases. The second-generation migrants refer to those who also tended to marry before leaving home but typically stayed longer in the city and lived separated from their spouse/children (Wu and Xie 2006). New 
generation migrant workers are generally thought to have some different characteristics and behaviour patterns from previous generations of migrant workers (Wang 2001).

5. Ling is Xioahua's mother's sister's eldest daughter.

6. According to Hsu's ethnography (1971), individual competition in traditional Chinese society was fierce, even though the society emphasised harmony and collectivity. The competition among individuals starts in the family among brothers. In 'competition with Chinese characteristics', the authority of the ancestors, i.e. patriarchal authority, is the key factor. The brothers do not fight for their own path; on the contrary, they fight for their father's favouritism (Hsu 1971: 246-47, 267). Hsu argues: 'This competition is strictly circumscribed by the authority of parents, ancestors and tradition. These several sources of authority dovetail into and re-enforce each other. They never conflict with one another. They provide the ground work and the limitation for both the means and the objects of this competition. In such a culture competitors are like the jockeys in a horse race; to win and achieve distinction they have to proceed along a given track toward the same destination. Any branching off along a different track or toward a different destination means total failure.' (Hsu 1971: 282)

7. In Western society, 'individuals form organizations. Each organization has its own boundaries, which dearly define those people who are members and those who are not. That much is always clear. The people in an organization form a group, and their relationship to the organization is usually the same. If there are differences among group members or distinctions among ranks within the organization, these would have been agreed upon earlier as part of the rules of the organization (Fei 1992: 61-62)'.

\section{REFERENCES}

Anagnost, A. (2004). The corporeal politics of quality (suzhi). Public Culture, 16(2), 189-208.

Anderson, B. (1983). Imagined communities: reflections on the origin and spread of nationalism. London: Verso.

Burawoy, M. (1979). Manufacturing consent: changes in the labor process under monopoly capitalism. Chicago, London: University of Chicago Press.

Carrier, J. G. (1992). Emerging alienation in production: A Maussian history. Man, New Series, 27(3), 539-558.

Carsten, J. (2004). After kinship. Cambridge: Cambridge University Press.

Chan, A. (2001). China's workers under assault: the exploitation of labor in a globalizing economy. Armonk, N.Y: M.E. Sharpe.

Chan, A., \& Wang, H.Z. (2004). The Impact of the State on Workers' Conditions - Comparing Taiwanese Factories in China and Vietnam. Pacific Affairs, 77(4), 629-646.

Crissman, L. W. (1972). Marketing in the Changhua Plain, Taiwan. In Economic Organization in Chinese Society, edited by W. E. Willmot, 215-260. Stanford: Stanford University Press.

Fei, H. (1992). From the soil, the foundations of Chinese society: a translation of Fei Xiaotong's Xiangtu Zhongguo. Berkeley: University of California Press.

Gates, H. (1996). China's motor: a thousand years of petty capitalism. Ithaca: Cornell University Press.

Humphrey, C. (2002). "The villas of the "new Russians': A sketch of consumption and cultural Identity." In The Unmaking of Soviet Life: Everyday Economies after Socialism, edited by C. Humphrey, 175-201. Ithaca and London: Cornell University Press.

Kipnis, A. B. (1997). Producing Guanxi: Sentiment, Self, and Subculture in a North China Village. Durham, NC: Duke University Press.

Kuever, E. (2019). Moral imaginings of the market and the state in contemporary China. Economic Anthropology, 6, 98-109.

Liew, L. (2005). China's Engagement with Neo-liberalism: Path Dependency, Geography and Party

Self-reinvention. Journal of Development Studies, 41(2), 331-352.

Leonard, M. (2008). What Does China Think? London: Harper Collins.

MacCormack, G. (1990). Traditional Chinese Penal Law. Edinburgh: Edinburgh University Press. 
Mann, S. (1987). Local Merchants and the Chinese Bureaucracy, 1750-1950. Stanford: Stanford University Press.

Mueggler, E. (1990). The age of wild ghosts: memory, violence, and place in Southwest China. Berkeley: University of California Press.

Nonini, D. M. (2008). Is China Becoming Neoliberal? Critique of Anthropology, 28(2), 145-176.

Ong, A. (2007). Neoliberalism as exception: mutations in citizenship and sovereignty. Durham, N.C: Duke University Press.

Potter, S. H., \& Potter, J. M. (1990). China's Peasants: The Anthropology of a Revolution. Cambridge: Cambridge University Press.

Pun, N. (2005). Made in China: Women Factory Workers in a Global Workplace. Durham: Duke University Press.

Pun, N., \& Lu, H. (2010). Unfinished Proletarianization: Self, Anger, and Class Action among the Second Generation of Peasant-Workers in Present-Day China. Modern China, 36(5), 493-519.

Rofel, L. (2007). Desiring China: experiments in neoliberalism, sexuality, and public culture. Durham: Duke University Press.

Rojas, C. (2016). Introduction: Specters of Marx, Shades of Mao, and the Ghosts of Global Capital. In Ghost Protocol: Development and Displacement in Global China, edited by C. Rojas and R.A. Litzinger, 1-12. Durham: Duke University Press.

Sanchez, A. (2012). Deadwood and paternalism: rationalizing casual labour in an Indian company town. Journal of the Royal Anthropological Institute (N.S.), 18(4), 808-827.

Shevchenko, O. (2009). Crisis and the everyday in postsocialist Moscow. Bloomington: Indiana University Press.

Shirk, S. (2010). The decline of virtuocracy in China" In Class and social stratification in post-revolution China, edited by J. L. Watson, 56-83. Cambridge: Cambridge University Press.

Shirk, S. L. (1982). Competitive comrades: career incentives and student strategies in China. Berkeley: University of California Press.

Skinner, W. G. (1964-65). Marketing and Social Structure in Rural China, Parts 1-3. Journal of Asian Studies, 24(1-3).

Solinger, D. J. (1999). Contesting citizenship in urban China: Peasant migrants, the state, and the logic of the market. Berkeley: University of California Press.

Stockman, N. (1992). Market, Plan and Structured Social Inequality in China. In Contesting Markets: analyses of ideology, discourse and practice, edited by R. Dilley, 260-276. Edinburgh: Edinburgh University Press.

Walder, A. G. (1986). Communist Neo-traditionalism: work and authority in Chinese industry. Hong Kong: Oxford University Press.

Yan, Y. (1999). Rural Youth and Youth Culture in North China. Culture Medicine and Psychiatry, 23(1), 75-97.

Yan, Y. (2003). Private life under socialism: love, intimacy, and family change in a Chinese village, 1949-1999. Stanford, Calif: Stanford University Press.

Yan, Y. (2010). The Chinese path to individualization. The British Journal of Sociology, 61(3), 489-511.

Yang, M. H-H. (1994). Gifts, favors, and banquets: the art of social relationships in China. Ithaca, N.Y: Cornell University Press.

Ye, J., \& Pan, L. (2011). Differentiated childhoods: impacts of rural labor migration on left-behind children in China. Journal of Peasant Studies, 38(2), 355-377.

Zhou, X-H. (1999). Cultural feedback: cultural transition between parents and their children in changing society. Yingyong xinli yanjiu (Applied Psychology Research), 4, 29-56.

Zhu, Y. (2004). Workers, Unions and the State: Migrant Workers in China's Labour-intensive Foreign Enterprises. Development and Change, 35(5), 1011-1036 